\title{
Genetic Determinants of Response to Warfarin during Initial Anticoagulation
}

\author{
Ute I. Schwarz, M.D., Marylyn D. Ritchie, Ph.D., Yuki Bradford, M.S., Chun Li, Ph.D., Scott \\ M. Dudek, B.S., Amy Frye-Anderson, R.N., Richard B. Kim, M.D., Dan M. Roden, M.D., and \\ C. Michael Stein, M.D. \\ Departments of Medicine and Pharmacology (U.I.S., A.F.-A., R.B.K., D.M.R., C.M.S.), the \\ Department of Molecular Physiology and Biophysics and the Center for Human Genetics \\ Research (M.D.R., Y.B., S.M.D.), and the Department of Biostatistics (C.L.), Vanderbilt University \\ School of Medicine, Nashville.
}

\section{Abstract \\ BACKGROUND-Genetic variants of the enzyme that metabolizes warfarin, cytochrome P-450 2C9 (CYP2C9), and of a key pharmacologic target of warfarin, vitamin $\mathrm{K}$ epoxide reductase (VKORC1), contribute to differences in patients' responses to various warfarin doses, but the role of these variants during initial anticoagulation is not clear.}

METHODS-In 297 patients starting warfarin therapy, we assessed CYP2C9 genotypes (CYP2C9 $* 1$, *2, and *3), VKORCl haplotypes (designated A and non-A), clinical characteristics, response to therapy (as determined by the international normalized ratio [INR]), and bleeding events. The study outcomes were the time to the first INR within the therapeutic range, the time to the first INR of more than 4, the time above the therapeutic INR range, the INR response over time, and the warfarin dose requirement.

RESULTS-As compared with patients with the non-A/non-A haplotype, patients with the A/A haplotype of VKORCl had a decreased time to the first INR within the therapeutic range $(\mathrm{P}=$ $0.02)$ and to the first INR of more than $4(\mathrm{P}=0.003)$. In contrast, the CYP2C9 genotype was not a significant predictor of the time to the first INR within the therapeutic range $(\mathrm{P}=0.57)$ but was a significant predictor of the time to the first INR of more than $4(\mathrm{P}=0.03)$. Both the CYP2C9 genotype and $V K O R C 1$ haplotype had a significant influence on the required warfarin dose after the first 2 weeks of therapy.

CONCLUSIONS-Initial variability in the INR response to warfarin was more strongly associated with genetic variability in the pharmacologic target of warfarin, VKORC1, than with CYP2C9.

Oral anticoagulation with the vitamin $\mathrm{K}$ antagonist warfarin reduces the rate of thromboembolic events for patients in a variety of clinical settings. ${ }^{1}$ However, warfarin therapy is challenging because there is wide variation among patients in response and therefore in dose requirement. To achieve and maintain an optimal warfarin dose, the prothrombin time and the international normalized ratio (INR) are monitored, and doses are adjusted to maintain each patient's INR within a narrow therapeutic range. An INR of less than 2 is associated with an increased risk of thromboembolism, ${ }^{2}$ and an INR of 4 or more is associated with an increased risk of bleeding. ${ }^{3}$

Copyright $\odot 2008$ Massachusetts Medical Society.

No potential conflict of interest relevant to this article was reported. 
Polymorphisms in the gene encoding the cytochrome P-450 2C9 enzyme (CYP2C9) are known to contribute to variability in sensitivity to warfarin. CYP2C9 is the enzyme primarily responsible for the metabolic clearance of the $S$-enantiomer of warfarin. ${ }^{4,5}$ Patients with certain common genetic variants of $C Y P 2 C 9$ require a lower dose of warfarin and a longer time to reach a stable dose. They are also at higher risk for over-anticoagulation and serious bleeding. 6,7

Vitamin K epoxide reductase (VKORC1) recycles vitamin K epoxide to the reduced form of vitamin $\mathrm{K}$, an essential cofactor in the formation of the active clotting factors II, VII, IX, and $\mathrm{X}$ through $\gamma$-glutamyl carboxylation. ${ }^{8}$ VKORC1 is the target of coumarin anticoagulants, and its common genetic variants result in altered sensitivity to warfarin. VKORC1 polymorphisms are associated with a need for lower doses of warfarin during longterm therapy ${ }^{9-19}$ and, in some studies, were found to contribute to the variation in dose requirement more than $C Y P 2 C 9$ variants.

On the basis of these observations, the Food and Drug Administration (FDA) approved a labeling change for warfarin that describes the reported effects of VKORCl and CYP2C9 on dose requirements. ${ }^{20}$ The package insert as of August 2007 states that "lower initiation doses should be considered for patients with certain genetic variations in CYP2C9 and VKORC1 enzymes." The FDA also approved clinical tests for these genetic variants. ${ }^{21}$

However, there is little information about the relative contributions of VKORCI and $C Y P 2 C 9$ to the anticoagulation response in patients during the initiation of warfarin therapy. The first months of anticoagulant treatment are particularly problematic, since the safe and effective dose for an individual patient is not known and is determined empirically. Consequently, the risk of over-anticoagulation, with the potential for hemorrhagic complications, is higher during this time than subsequently. ${ }^{3,22,23}$ Therefore, genotyping in order to individualize the warfarin dose is likely to have the greatest effect during the initiation of treatment. Thus, we evaluated the effect of variant CYP2C9 and VKORC1 alleles in a cohort of patients that had been assembled prospectively to evaluate genetic contributions to the early phase of anticoagulation.

\section{METHODS}

\section{STUDY DESIGN AND ELIGIBILITY}

The study was conducted at three anticoagulation clinics affiliated with the Vanderbilt University Medical Center: the Pharmacy, Cardiology, and Arthritis and Joint Replacement Center clinics. Patients presenting for initiation of warfarin therapy were prospectively screened to determine eligibility for the study and were enrolled if they provided written informed consent. The center's institutional review board approved the study.

To be eligible, patients at least 18 years of age needed to have started warfarin therapy between July 2002 and July 2004. Exclusion criteria were a diagnosis of active cancer requiring, or with the potential to require, concurrent chemotherapy, as well as active alcoholism.

The target therapeutic INR range was determined by each patient's physician and varied according to the indication for warfarin treatment. Concurrent medications were categorized into groups of drugs that might potentiate or attenuate the anticoagulant effect of warfarin. ${ }^{1,24}$ Amiodarone, because of its marked effects, ${ }^{25}$ was considered separately. 


\section{DATA COLLECTION AND FOLLOW-UP}

A trained nurse collected study data by interviewing patients, reviewing their medical records, and obtaining a venous blood sample for DNA extraction. Recorded at baseline were the patient's age, sex, racial or ethnic background, indication for warfarin therapy, date of initiation of warfarin, target INR range, initial warfarin dose, and concomitant medications. Data regarding subsequent INR values and warfarin doses, the frequency of INR monitoring, and bleeding events were obtained from medical records. Information was recorded in an Oracle database. All patients were followed from the first date of warfarin use until the end of follow-up or the end of treatment at Vanderbilt University Medical Center; the latter was defined as the absence of an INR measurement in the medical record for more than 60 days. The closing date for data collection was July 12, 2004.

\section{GENOTYPING}

CYP2C9 genotyping was performed with the use of a fluorescent allele-specific oligonucleotide ligation assay after initial polymerase-chain-reaction amplification with the use of primers for the major variant alleles $C Y P 2 C 9 * 2(430 \mathrm{C} \rightarrow \mathrm{T}$; rs 1799853$),{ }^{26} \mathrm{CYP} 2 \mathrm{C} 9 * 3$ $(1075 \mathrm{~A} \rightarrow \mathrm{C}$; rs 1057910), and CYP2C9*5 (1080C $\rightarrow \mathrm{G} ;$ rs28371686), as described previously. ${ }^{27}$ (See Table 1 of the Supplementary Appendix, available with the full text of this article at www.nejm.org.) The frequencies of $C Y P 2 C 9 * 2$ and $C Y P 2 C 9 * 3$ variant alleles are 8 to $19 \%$ and 3 to $16 \%$, respectively, in white populations, and the frequency of the CYP2C $* 5$ variant allele is 0.2 to $1.7 \%$ in black populations. ${ }^{28}$

VKORCl genotyping for known variants with functional importance within the promoter $(-1639 \mathrm{G} \rightarrow \mathrm{A}$ or 3673 [rs9923231]) and intronic regions $-497 \mathrm{~T} \rightarrow \mathrm{G}$ or 5808 (rs2884737), $1173 \mathrm{C} \rightarrow \mathrm{T}$ or 6484 (rs9934438), $1542 \mathrm{G} \rightarrow \mathrm{C}$ or 6853 (rs8050894), and $2255 \mathrm{C} \rightarrow \mathrm{T}$ or 7566 (rs2359612) - was performed with the use of single-nucleotide polymorphism (SNP) assay (Custom TaqMan) (Table 2 of the Supplementary Appendix) or TaqMan Validated SNP assays (C_2847860_10 and C_26291751_ 10) with the 7900HT Sequence Detection System (Applied Biosystems). Patients were assigned to the VKORC1 haplotype group A with the use of five VKORCl variants, numbered according to the GenBank accession number AY587020 genomic sequence at positions $3673,5808,6484,6853$, and 7566, as described previously. ${ }^{9}$ All other patients were assigned to a haplotype group termed non-A, which corresponds closely to the VKORC1 haplotype group B, as described by Rieder et al. ${ }^{9}$ Haplotypes A and B together account for 96 to $99 \%$ of the total haplotypes in white Americans. ${ }^{9}$

\section{PRIMARY AND SECONDARY OUTCOMES}

We prespecified four primary outcomes for analysis. We calculated the time to the first INR within the therapeutic range and the time to the first INR of more than 4 from the date that warfarin was started. Both of these outcomes were selected specifically to assess the effect of $C Y P 2 C 9$ genotypes and VKORCl haplotypes on the effect of warfarin during initiation of anticoagulation.

We selected two additional primary outcomes to assess the effect of CYP2C9 and VKORC1 during a longer interval. The time that the patient's INR was above the therapeutic range relative to the complete time of follow-up was calculated by interpolation; the difference between an INR value and the subsequent value was divided by the number of days between these two measurements to establish an average daily increment or decrement. ${ }^{29}$ Interpolated INR values were used to calculate the time that patients spent above their individual INR range, relative to the duration of exposure to warfarin. The INR response over time was determined by comparing the average INR value among genotypes during weeks 1 and 2 and during the period between day 29 and the end of follow-up. 
Prespecified secondary outcomes included the average daily warfarin dose and bleeding events. The average warfarin daily dose (in milligrams per day) was determined during weeks 1 and 2 and between day 29 and the end of follow-up. In addition, major and minor bleeding events were counted according to the criteria of the Second Copenhagen Atrial Fibrillation, Aspirin, and Anticoagulation study. ${ }^{30}$

\section{STATISTICAL ANALYSIS}

We assessed linkage disequilibrium for the VKORC1 polymorphisms $3673,6484,6853$, and 7566 by calculating the square of the correlation coefficient $\left(\mathrm{r}^{2}\right)$ for each pair of variants with the use of genetic-marker data analysis (PowerMarker). ${ }^{31}$ The individual haplotypes of patients were estimated for VKORC1 and used for subsequent analyses. Tests for HardyWeinberg equilibrium in the population were performed with the use of Haploview software. ${ }^{32}$ Frequencies of CYP2C9 genotypes and VKORC1 haplotypes among racial groups were compared with the use of chi-square tests of independence. The characteristics of the patients were compared in the CYP2C9 genotype groups and the VKORC1 haplotype groups with the use of Student's t-test, the chi-square test, or Fisher's exact test, as appropriate.

The primary outcomes of the time to the first INR within the therapeutic range and to the first INR of more than 4 were compared among genotype or haplotype groups with the use of log-rank tests. Cox regression analyses were performed to determine the hazard ratio for achieving a first INR within the therapeutic range or a first INR of more than 4 in the first 4 weeks and during the entire follow-up period, according to genotype or haplotype group. We prospectively selected potentially confounding variables, including age, race, sex, use of amiodarone, target INR, starting warfarin dose, number of INR tests, and indication for anticoagulation, to adjust comparisons among genotypes and haplotypes. The primary outcome of the time above the therapeutic INR range was compared according to genotype or haplotype with the use of a Kruskal-Wallis ranksum test for the overall comparison and the Tukey-Kramer honest-significant-differences test for pairwise comparisons. The primary outcome of INR response to warfarin during various time periods was explored with the use of the Kruskal-Wallis rank-sum test to determine whether there was an effect of genotype or haplotype on the INR. The prespecified secondary outcome of the average dose of warfarin was compared among genotypes and haplotypes with the use of Student's t-test.

Data are presented as means $( \pm \mathrm{SD})$ or as medians with interquartile ranges, as appropriate. All standard statistical tests were performed with the use of SAS software, version 9.1 (SAS Institute). All P-values are two-sided. No statistical corrections for multiple testing were performed.

\section{RESULTS \\ POPULATION CHARACTERISTICS}

Of the 325 patients who met the entry criteria, 28 were excluded from the analysis for the following reasons (some patients had more than one reason): 7 patients had no INR readings in the first 10 days after the start of warfarin treatment, 12 patients had fewer than two INR readings, 6 patients had no target INR recorded or the target INR was outside the range of 1.8 to 3.5, 3 patients provided no DNA or the DNA was of poor quality, 3 patients had incomplete baseline data collection, 1 patient did not provide a blood sample, 1 patient did not have a recorded start date for warfarin, and 1 patient was undergoing chemotherapy. These exclusions resulted in a final study population of 297 patients. 
Table 1 summarizes the characteristics of the patients. The target INR ranged from 1.8 to 3.5 and was 2 to 3 in $69 \%$ of the patients. The average initial warfarin dose was $4.8 \pm 0.8 \mathrm{mg}$. There was no significant difference among patients with the various $C Y P 2 C 9$ genotypes and VKORCI haplotypes with respect to age, sex, underlying diagnosis, target INR, initial warfarin dose, and proportion of patients receiving concomitant drugs that could potentiate or attenuate the effect of warfarin. The mean numbers of INR measurements during the first 28 days and the entire study period were $7.7 \pm 3.8$ and $12.4 \pm 6.4$, respectively, and did not differ significantly among patients with $C Y P 2 C 9$ genotypes and VKORC1 haplotypes ( $\mathrm{P}>0.30$ for all comparisons). The median follow-up interval was 43 days.

\section{ALLELIC FREQUENCIES}

The promoter and intronic VKORC1 polymorphisms 3673, 6484, 6853, and 7566 were in strong linkage disequilibrium $\left(\mathrm{r}^{2} \geq 0.85\right)$. The allelic frequency of haplotype A was $32.6 \%$, including 129 heterozygotes and 32 homozygotes (Table 2), and was significantly lower among black patients (13.8\%) than among white patients $(34.3 \%)(\mathrm{P}=0.006)$.

The allelic frequencies of $C Y P 2 C 9 * 2$ and $C Y P 2 C 9 * 3$ were $12.0 \%$ and $4.8 \%$, respectively. $C Y P 2 C 9 * 5$ was not found in any of the patients. For analysis, $C Y P 2 C 9$ genotypes were considered in three groups: $C Y P 2 C 9 * 1 / * 1$ (wild type), $C Y P 2 C 9 * 1 / * 2$ and $C Y P 2 C 9 * 1 / * 3$ (heterozygotes), and $C Y P 2 C 9 * 2 / * 2, C Y P 2 C 9 * 3 / * 3$, and $C Y P 2 C 9 * 2 / * 3$ (homozygotes and compound heterozygotes). The frequency of the $C Y P 2 C 9$ genotype groups varied significantly among racial or ethnic groups $(\mathrm{P}=0.005)$ (Table 2$)$. There was no deviation from the expected proportions of genotypes in the population predicted by the HardyWeinberg equilibrium for polymorphisms in VKORC1, CYP2C9*2, and CYP2C9*3.

\section{TIME TO FIRST INR IN THERAPEUTIC RANGE AND FIRST INR ABOVE 4}

Figure 1 shows the primary outcomes of the times to the first therapeutic INR and to the first INR of more than 4 among various genotypes. The VKORCl haplotype had a significant effect on the time that was required to reach the first INR within the therapeutic range $(\mathrm{P}=$ $0.02)$ and the time to the first INR of more than $4(\mathrm{P}=0.003)$ (Fig. 1A and 1B and Table 3$)$. Patients with one or two VKORC1 haplotype A alleles had shorter times to the first INR within the therapeutic range and to an INR of more than 4 than did patients with two haplotype non-A alleles (Table 4). Concordant with these findings, Cox regression analysis with statistical adjustment for potentially confounding covariates showed that among A/A homozygotes, the rate of achieving a first INR within the therapeutic range (both during the initial 28 days and the entire follow-up period) was higher than that of non-A/non-A homozygotes by a factor of nearly 2.4 ( $\mathrm{P}<0.001$ for both comparisons); the rate of reaching an INR of more than 4 was higher by more than a factor of 2.5 during the corresponding periods ( $\mathrm{P}=0.009$ for both comparisons) (Table 4$)$. Patients carrying only one A allele were also at higher risk.

In contrast, the $C Y P 2 C 9$ genotype did not significantly affect the time to the first INR within the therapeutic range (Tables 3 and 4 and Fig. 1C). Carriers of $C Y P 2 C 9 * 2$ and $C Y P 2 C 9 * 3$ variant alleles did reach a first INR of more than 4 earlier than did patients with the wildtype allele $(\mathrm{P}=0.03)$ (Fig. 1D). This finding was reflected in an increased hazard ratio (Table 4).

\section{TIME ABOVE THE THERAPEUTIC INR RANGE}

The VKORCl haplotype had a significant effect on the primary outcome of the percentage of time above the therapeutic INR range $(\mathrm{P}=0.03)$. Patients who were homozygous for VKORC1 haplotype A spent significantly more treatment time above their therapeutic INR range than did patients who were homozygous for the non-A haplotype (median percentage, 
$18.8 \%$ vs. $9.1 \% ; \mathrm{P}=0.02$ ). The association between the $C Y P 2 C 9$ genotype and the time above the therapeutic INR range was weaker and not statistically significant $(\mathrm{P}=0.09)$.

\section{INR RESPONSE OVER TIME}

Genotype differences in INR were more marked early in therapy, probably because the dose of warfarin was titrated according to the INR; therefore, later INR responses reflected this titration (Table 5). The primary outcome of the average INR response was significantly affected by the VKORC1 haplotype during the first 2 weeks of treatment $(\mathrm{P}<0.001$ for both week 1 and week 2); this relationship was weaker for the CYP2C9 genotype groups $(\mathrm{P}=$ 0.17 for week 1 and $\mathrm{P}=0.04$ for week 2).

\section{SINGLE-GENE EFFECTS ON WARFARIN DOSE REQUIREMENT}

The VKORCI haplotype affected the prespecified secondary outcome of average warfarin dose in weeks 1 and 2 and from day 29 to the end of follow up ( $\mathrm{P}<0.001$ for all comparisons) (Table 5). There was a gene-dose effect, with haplotype A associated with a higher INR response requiring lower doses of warfarin. The $C Y P 2 C 9$ genotype was also associated with the warfarin dose, but the effect was less marked during the first 2 weeks of therapy than after the first 28 days (Table 5).

\section{BLEEDING RISK}

The risk of bleeding was assessed as a prespecified secondary outcome. There were eight major and five minor bleeding events involving 12 patients (1 patient had two events), as defined by the Second Copenhagen Atrial Fibrillation, Aspirin, and Anticoagulation study ${ }^{30}$ (Table 3 of the Supplementary Appendix). The majority of bleeding events ( 9 of 13) occurred within the first 28 days after the initiation of warfarin treatment at a mean dose of $4.4 \pm 1.4 \mathrm{mg}$ per day and a median INR of 3.7 (range, 1.7 to 12.3). Patients with bleeding events were older (median age, 71 years) than the study population (median age, 61 years). Two patients with bleeding events were homozygous for $C Y P 2 C 9 * 2$, three were heterozygous (one patient had $C Y P 2 C 9 * 1 / * 2$, and two patients had $C Y P 2 C 9^{*} 1 / * 3$ ), and seven had $C Y P 2 C 9^{*} 1 / * 1$. Three patients were homozygous for VKORC1 haplotype non-A, seven were heterozygous for non-A/A, and two were homozygous for A.

\section{DISCUSSION}

This study of patients who were starting warfarin therapy investigated the relationship between VKORC1 haplotypes and CYP2C9 genotypes and the INR responses that are used to adjust doses. The major finding was that genetic variation in VKORCl, but not in CYP2C9, modulates the early response to warfarin.

We found that patients carrying VKORCl haplotype A had significantly higher INR values in the first week than did non-A homozygotes. These differences in response occurred despite empiric dose adjustment of warfarin. In contrast, the CYP2C9 genotype did not significantly affect INR responses during the first week. We also found that the VKORCI haplotype predicted both the time to the first INR within the therapeutic range and the time to the first INR of more than 4. Among patients who were carrying two A alleles, the rate of reaching these outcomes at given time intervals was approximately twice that of non-A homozygotes; patients with one A allele also showed an increased risk of reaching an INR above 4 .

Most recent studies of the role of genetic variants in the response to warfarin enrolled patients receiving stable anticoagulation ${ }^{13,15-18,33}$ or those who had undergone 1 to 3 months of warfarin pretreatment. ${ }^{10,11,14}$ Studies that enrolled patients who were just starting 
therapy have primarily focused on differences in the warfarin dose. ${ }^{9,12}$ Two studies analyzing the first few weeks of warfarin treatment showed that among carriers of the $C Y P 2 C 9 * 2$ or $C Y P 2 C 9 * 3$ allele, the proportion of patients with INR values of more than 3 was higher than that of patients who were not carriers. ${ }^{34,35}$ However, in a study in which the prospective dose of warfarin was based on CYP2C9 genotype, carriers of a variant allele had an increased risk of having an INR of more than $4 .{ }^{36}$

Our findings contrast with those of a recent study by Millican et al. ${ }^{37}$ that examined the use of clinical and genetic variables for predicting the maintenance dose of warfarin in 92 patients. In that study, genotyping for VKORCI contributed little to the final statistical model; the INR after the third dose of warfarin was the strongest predictor of the maintenance dose. As we have shown, the early INR response is strongly affected by the VKORC1 haplotype. Thus, as shown by Millican et al., the contribution of VKORCI was captured in the INR after three doses of warfarin.

An increase in the anticoagulant response over time (as indicated by an INR above the therapeutic range) is associated with an increased risk of bleeding. ${ }^{3}$ Therefore, in addition to the time to the first INR of more than 4 , the amount of time spent above the therapeutic INR range is informative. In our study, the VKORCl haplotype affected the time that patients spent above the therapeutic INR range, whereas the CYP2C9 genotype had a marginal effect. However, both the VKORC1 haplotype and the CYP2C9 genotype had a significant effect on the warfarin dose after the first 2 weeks. Our results confirm the relationship between the CYP2C9 genotype and the response to warfarin that has been observed by others, ${ }^{6,36,38}$ but they also indicate that early in the course of anticoagulation the effect of the VKORC1 haplotype is greater than that of the CYP2C9 genotype, and the presence of a $V K O R C 1 \mathrm{~A}$ allele is associated with an accelerated and greater sensitivity to warfarin.

Serious bleeding events were not significantly affected by the presence of the VKORC1 haplotype or CYP2C9 genotype. However, our study focused on changes in the INR and the warfarin dose during the first few weeks of therapy and not with therapy of longer duration, so the number of events was small.

In conclusion, during the initial phase of anticoagulation, genetic variants of VKORCl are a major determinant of variability in sensitivity to warfarin among patients. Genetic variants of $C Y P 2 C 9$, in contrast, appear to have limited influence during the initiation of warfarin therapy.

\section{Supplementary Material}

Refer to Web version on PubMed Central for supplementary material.

\section{Acknowledgments}

Supported by the following grants from the National Institutes of Health: a Pharmacogenetics Research Network Grant (U01-HL65962), HL04012, and GM31304. Data presented here have been deposited at the Pharmacogenetics Knowledge Base, which is supported by grant U01-GM61374.

\section{REFERENCES}

1. Ansell J, Hirsh J, Poller L, Bussey H, Jacobson A, Hylek E. The pharmacology and management of the vitamin K antagonists: the Seventh ACCP Conference on Antithrombotic and Thrombolytic Therapy. Chest. 2004; 126(3 Suppl):204S-233S. Erratum, Chest 2005;127:415-6. [PubMed: 15383473] 
2. Kearon C, Ginsberg JS, Kovacs MJ, et al. Comparison of low-intensity warfarin therapy with conventional-intensity warfarin therapy for long-term prevention of recurrent venous thromboembolism. N Engl J Med. 2003; 349:631-659. [PubMed: 12917299]

3. Levine MN, Raskob G, Landefeld S, Kearon C. Hemorrhagic complications of anticoagulant treatment. Chest. 2001; 119(Suppl 1):108S-121S. [PubMed: 11157645]

4. Takahashi H, Wilkinson GR, Padrini R, Echizen H. CYP2C9 and oral anticoagulation therapy with acenocoumarol and warfarin: similarities yet differences. Clin Pharmacol Ther. 2004; 75:376-380. [PubMed: 15116049]

5. Kaminsky LS, Zhang ZY. Human P450 metabolism of warfarin. Pharmacol Ther. 1997; 73:97-123.

6. Higashi MK, Veenstra DL, Kondo LM, et al. Association between CYP2C9 genetic variants and anticoagulation-related outcomes during warfarin therapy. JAMA. 2002; 287:1690-1699. [PubMed: 11926893]

7. Veenstra DL, Blough DK, Higashi MK, et al. CYP2C9 haplotype structure in European American warfarin patients and association with clinical outcomes. Clin Pharmacol Ther. 2005; 77:353-364. [PubMed: 15900281]

8. Cain D, Hutson SM, Wallin R. Assembly of the warfarin-sensitive vitamin K 2,3-epoxide reductase enzyme complex in the endoplasmic reticulum membrane. J Biol Chem. 1997; 272:29068-29075. [PubMed: 9360981]

9. Rieder MJ, Reiner AP, Gage BF, et al. Effect of VKORC1 haplotypes on transcriptional regulation and warfarin dose. N Engl J Med. 2005; 352:2285-2393. [PubMed: 15930419]

10. Veenstra DL, You JH, Rieder MJ, et al. Association of Vitamin K epoxide reductase complex 1 (VKORC1) variants with warfarin dose in a Hong Kong Chinese patient population. Pharmacogenet Genomics. 2005; 15:687-791. [PubMed: 16141794]

11. Wadelius M, Chen LY, Downes K, et al. Common VKORC1 and GGCX polymorphisms associated with warfarin dose. Pharmacogenomics J. 2005; 5:262-270. [PubMed: 15883587]

12. D'Andrea G, D'Ambrosio RL, Di Perna P, et al. A polymorphism in the VKORC1 gene is associated with an interindividual variability in the dose-anticoagulant effect of warfarin. Blood. 2005; 105:645-699. [PubMed: 15358623]

13. Sconce EA, Khan TI, Wynne HA, et al. The impact of CYP2C9 and VKORC1 genetic polymorphism and patient characteristics upon warfarin dose requirements: proposal for a new dosing regimen. Blood. 2005; 106:2329-2433. [PubMed: 15947090]

14. Takahashi H, Wilkinson GR, Nutescu EA, et al. Different contributions of polymorphisms in VKORC1 and CYP2C9 to intra- and inter-population differences in maintenance dose of warfarin in Japanese, Caucasians and African-Americans. Pharmacogenet Genomics. 2006; 16:101-110. [PubMed: 16424822]

15. Lee SC, $\mathrm{Ng} \mathrm{SS}$, Oldenburg J, et al. Interethnic variability of warfarin maintenance requirement is explained by VKORC1 genotype in an Asian population. Clin Pharmacol Ther. 2006; 79:197-205. [PubMed: 16513444]

16. Vecsler M, Loebstein R, Almog S, et al. Combined genetic profiles of components and regulators of the vitamin K-dependent gamma-carboxylation system affect individual sensitivity to warfarin. Thromb Haemost. 2006; 95:205-311. [PubMed: 16493479]

17. Herman D, Peternel P, Stegnar M, Breskvar K, Dolzan V. The influence of sequence variations in factor VII, gamma-glutamyl carboxylase and vitamin K epoxide reductase complex genes on warfarin dose requirement. Thromb Haemost. 2006; 95:782-797. [PubMed: 16676068]

18. Aquilante CL, Langaee TY, Lopez LM, et al. Influence of coagulation factor, vitamin K epoxide reductase complex subunit 1 , and cytochrome $\mathrm{P} 450$ 2C9 gene polymorphisms on warfarin dose requirements. Clin Pharmacol Ther. 2006; 79:291-302. [PubMed: 16580898]

19. Li T, Lange LA, Li X, et al. Polymorphisms in the VKORC1 gene are strongly associated with warfarin dosage requirements in patients receiving anticoagulation. J Med Genet. 2006; 43:740 874. [PubMed: 16611750]

20. FDA approves updated warfarin (Coumadin) prescribing information. Press release of the Food and Drug Administration; 2007 Aug 16. at http://www.fda.gov/bbs/topics/NEWS/2007/ NEW01684.html. [Accessed February 11, 2008] 
21. FDA clears genetic lab test for warfarin sensitivity. Press release of the Food and Drug Administration; 2007 Sep 17. at http://www.fda.gov/bbs/topics/NEWS/2007/NEW01701.html [Accessed February 11, 2008]

22. Beyth RJ, Quinn L, Landefeld CS. A multicomponent intervention to prevent major bleeding complications in older patients receiving warfarin: a randomized, controlled trial. Ann Intern Med. 2000; 133:687-795. [PubMed: 11074901]

23. McMahan DA, Smith DM, Carey MA, Zhou XH. Risk of major hemorrhage for outpatients treated with warfarin. J Gen Intern Med. 1998; 13:311-426. [PubMed: 9613886]

24. Micromedex Healthcare Series. Drugdex System (Internet database). Greenwood Village, CO: Thomson Healthcare; at http:www.micromedex.com/products/drugdex. [Accessed February 11, 2008]

25. Gage BF, Eby C, Milligan PE, Banet GA, Duncan JR, McLeod HL. Use of pharmacogenetics and clinical factors to predict the maintenance dose of warfarin. Thromb Haemost. 2004; 91:87-94. [PubMed: 14691573]

26. Sullivan-Klose TH, Ghanayem BI, Bell DA, et al. The role of the CYP2C9-Leu359 allelic variant in the tolbutamide polymorphism. Pharmacogenetics. 1996; 6:341-369. [PubMed: 8873220]

27. Dickmann LJ, Rettie AE, Kneller MB, et al. Identification and functional characterization of a new CYP2C9 variant (CYP2C9*5) expressed among African Americans. Mol Pharmacol. 2001; 60:382-397. [PubMed: 11455026]

28. Xie HG, Prasad HC, Kim RB, Stein CM. CYP2C9 allelic variants: ethnic distribution and functional significance. Adv Drug Deliv Rev. 2002; 54:1257-1370. [PubMed: 12406644]

29. Rosendaal FR, Cannegieter SC, van der Meer FJ, Briët E. A method to determine the optimal intensity of oral anticoagulant therapy. Thromb Haemost. 1993; 69:236-269. [PubMed: 8470047]

30. Gullov AL, Koefoed BG, Petersen P. Bleeding during warfarin and aspirin therapy in patients with atrial fibrillation: the AFASAK 2 study. Arch Intern Med. 1999; 159:1322-1368. [PubMed: 10386508]

31. Liu K, Muse SV. PowerMarker: an integrated analysis environment for genetic marker analysis. Bioinformatics. 2005; 21:2128-2239. [PubMed: 15705655]

32. Barrett JC, Fry B, Maller J, Daly MJ. Haploview: analysis and visualization of LD and haplotype maps. Bioinformatics. 2005; 21:263-265. [PubMed: 15297300]

33. Carlquist JF, Horne BD, Muhlestein JB, et al. Genotypes of the cytochrome p450 isoform, CYP2C9, and the vitamin K epoxide reductase complex subunit 1 conjointly determine stable warfarin dose: a prospective study. J Thromb Thrombolysis. 2006; 22:191-197. [PubMed: 17111199]

34. Peyvandi F, Spreafico M, Siboni SM, Moia M, Mannucci PM. CYP2C9 genotypes and dose requirements during the induction phase of oral anticoagulant therapy. Clin Pharmacol Ther. 2004; 75:198-203. [PubMed: 15001971]

35. Lindh JD, Lundgren S, Holm L, Alfredsson L, Rane A. Several-fold increase in risk of overanticoagulation by CYP2C9 mutations. Clin Pharmacol Ther. 2005; 78:540-550. [PubMed: 16321620]

36. Voora D, Eby C, Linder MW, et al. Prospective dosing of warfarin based on cytochrome P-450 2C9 genotype. Thromb Haemost. 2005; 93:700-755. [PubMed: 15841315]

37. Millican EA, Lenzini PA, Milligan PE, et al. Genetic-based dosing in orthopedic patients beginning warfarin therapy. Blood. 2007; 110:1511-1695. [PubMed: 17387222]

38. Margaglione M, Colaizzo D, D'Andrea G, et al. Genetic modulation of oral anticoagulation with warfarin. Thromb Haemost. 2000; 84:775-878. [PubMed: 11127854] 


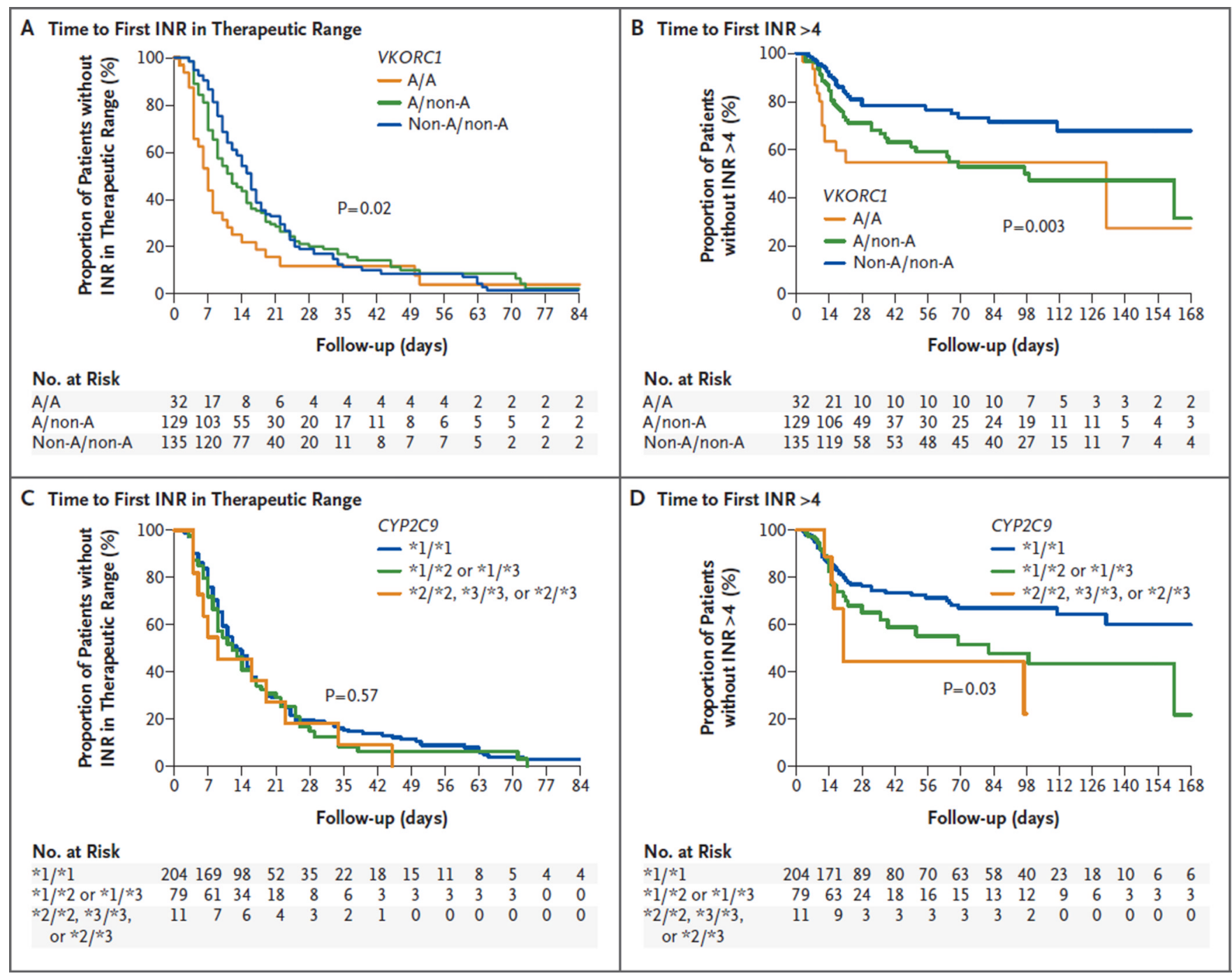

Figure 1. Association between Specific Genetic Variants and Study Outcomes

The graphs show the association between the time to the first international normalized ratio (INR) within the therapeutic range and the time to the first INR of more than 4 for patients carrying genetic variants for vitamin $\mathrm{K}$ epoxide reductase (VKORC1) (Panels A and $\mathrm{B}$ ) and for cytochrome P-450 2C9 (CYP2C9) (Panels C and D). 
Table 1

Characteristics of the 297 Patients.

\begin{tabular}{|c|c|}
\hline Variable & Value \\
\hline Female sex — no. $(\%)$ & $137(46.1)$ \\
\hline \multicolumn{2}{|c|}{ Race or ethnic background - no. $(\%)^{\dagger}$} \\
\hline White & $265(89.2)$ \\
\hline Black & $29(9.8)$ \\
\hline Hispanic & $3(1.0)$ \\
\hline Age $-\mathrm{yr}$ & $60.9 \pm 13.9$ \\
\hline \multicolumn{2}{|c|}{ Indication for treatment - no. $(\%)$} \\
\hline Atrial fibrillation or flutter & $107(36.0)$ \\
\hline Joint replacement & $121(40.7)$ \\
\hline Thrombosis or embolus & $40(13.5)$ \\
\hline Other or multiple indications & $33(11.1)$ \\
\hline \multicolumn{2}{|c|}{ Concomitant medication - no. $(\%)^{*}$} \\
\hline Potentiating medications & $218(73.4)$ \\
\hline Amiodarone & $39(13.1)$ \\
\hline Attenuating medications & $31(10.4)$ \\
\hline \multicolumn{2}{|l|}{ Follow-up — days } \\
\hline Median & 43 \\
\hline Interquartile range & $3-414$ \\
\hline \multicolumn{2}{|l|}{ No. of INR determinations } \\
\hline Median & 9 \\
\hline Interquartile range & $2-42$ \\
\hline
\end{tabular}

* Plus-minus values are means \pm SD. INR denotes international normalized ratio.

${ }^{\dagger}$ Race or ethnic background was reported by the patients.

${ }^{*}$ Concomitant medications include drugs that potentiate or attenuate the effect of warfarin. 
Table 2

Frequency of the VKORCl Haplotype and the CYP2C9 Genotype, According to Race.

\begin{tabular}{|lccc|}
\hline Variant & \multicolumn{3}{c}{ Frequency in American Population } \\
& White & Black & All Patients \\
VKORC1 haplotype & \multicolumn{3}{c}{ number (percent) } \\
\hline Non-A/non-A & $114(43.2)$ & $21(72.4)$ & $135(45.6)$ \\
\hline Non-A/A & $119(45.1)$ & $8(27.6)$ & $129(43.6)$ \\
\hline A/A & $31(11.7)$ & 0 & $32(10.8)$ \\
\hline Total & $264(100.0)$ & $29(100.0)$ & $296(100.0)$ \\
\hline CYP2C9 genotype & & & \\
\hline$* 1 / * 1$ & $176(66.7)$ & $27(96.4)$ & $204(69.4)$ \\
\hline$* 1 / * 2$ or *1/*3 & $77(29.2)$ & $1(3.6)$ & $79(26.9)$ \\
\hline$* 2 / * 2, * 3 / * 3$, or *2/*3 & $11(4.2)$ & 0 & $11(3.7)$ \\
\hline Total & $264(100.0)$ & $28(100.0)$ & $294(100.0)$ \\
\hline
\end{tabular}

* Genotyping could not be performed for one patient with the VKORC1 haplo-type and three patients with the CYP2C9 genotype. Percentages may not total 100 because of rounding.

${ }^{\dagger}$ This group included three Hispanic patients. 


\section{Table 3}

Median Times to the First INR within the Therapeutic Range and to the First INR of More Than 4, According to Variant.*

\begin{tabular}{|c|c|c|}
\hline $\begin{array}{l}\text { Haplotype } \\
\text { or Genotype }\end{array}$ & $\begin{array}{r}\text { Median Time to } \\
\text { First INR within } \\
\text { Therapeutic Range } \\
\text { days }\end{array}$ & $\begin{array}{c}\text { Median } \\
\text { Time to } \\
\text { First INR >4 }\end{array}$ \\
\hline \multicolumn{3}{|l|}{ VKORC1 } \\
\hline Non-A/Non-A & 15 & 23 \\
\hline Non-A/A & 11 & 20 \\
\hline $\mathrm{A} / \mathrm{A}$ & 7 & 17 \\
\hline \multicolumn{3}{|l|}{ СУР $2 C 9$} \\
\hline$* 1 / * 1$ & 12 & 22 \\
\hline$* 1 / * 2$ or $* 1 / * 3$ & 11 & 19 \\
\hline $\begin{array}{c}* 2 / * 2, * 3 / * 3, \\
\text { or } * 2 / * 3\end{array}$ & 9 & 18 \\
\hline
\end{tabular}

* Median times are given only for patients who reached the indicated primary outcome. Since the majority of patients in each group did not reach the primary outcome of the first international normalized ratio (INR) of more than 4 , the true medians may be longer. 
Table 4

Hazard Ratio for Primary Outcomes, According to VKORC1 or CYP2C9 Variant. "

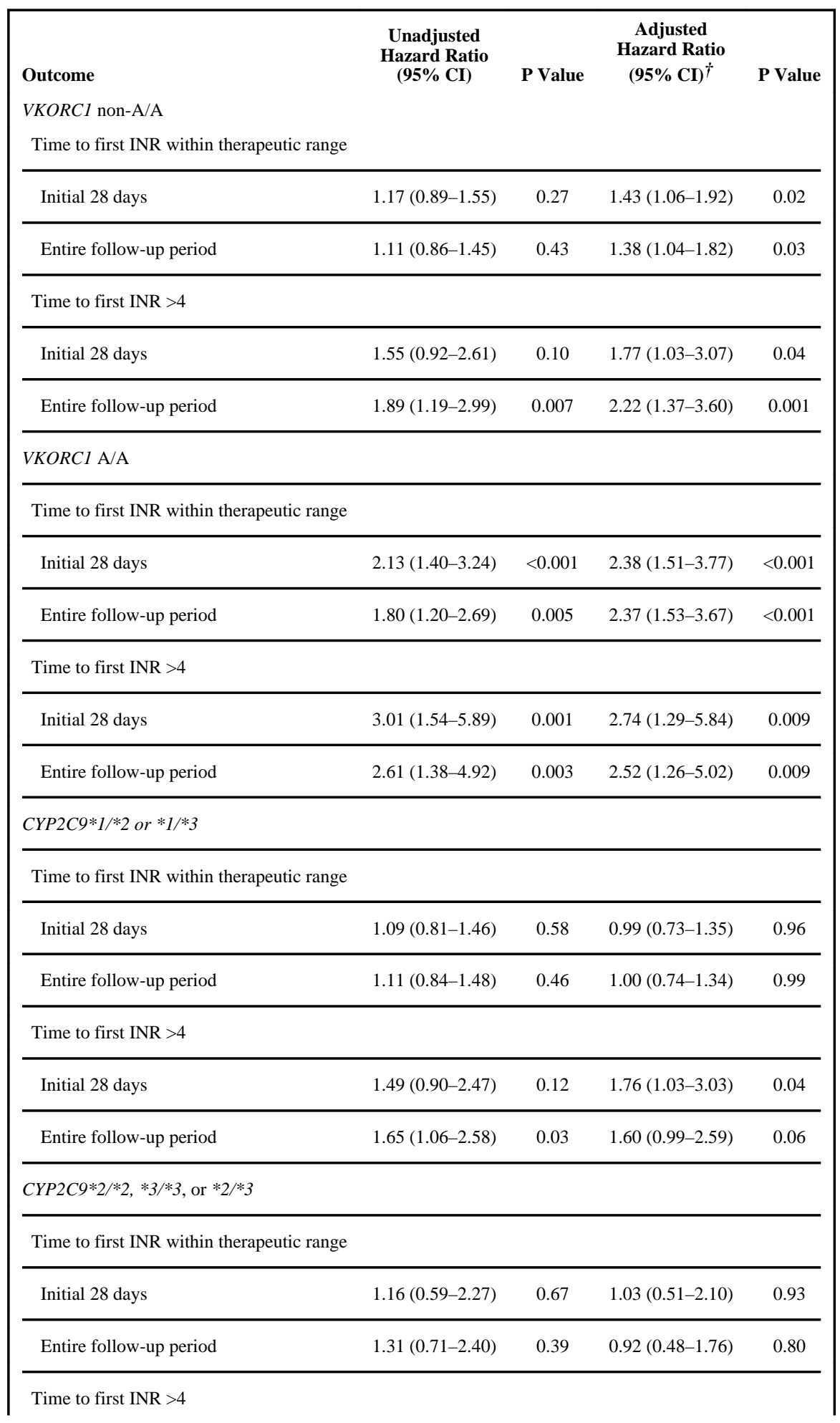




\begin{tabular}{|lccccc|}
\hline Outcome & $\begin{array}{c}\text { Unadjusted } \\
\text { Hazard Ratio } \\
(\mathbf{9 5 \%} \text { CI) }\end{array}$ & P Value & $\begin{array}{c}\text { Adjusted } \\
\text { Hazard Ratio } \\
\mathbf{( 9 5 \% ~ C I )}\end{array}$ & P Value \\
\hline Initial 28 days & $2.16(0.77-6.02)$ & 0.14 & $2.67(0.90-7.93)$ & 0.08 \\
\hline Entire follow-up period & $2.40(0.96-6.02)$ & 0.06 & $2.48(0.94-6.53)$ & 0.07 \\
\hline
\end{tabular}

* Hazard ratios are for patients with one or two copies of the VKORC1 group A allele as compared with the VKORC1 group non-A/non-A allele and for those with one or two copies of a CYP2C9 variant allele as compared with $C Y P 2 C 9^{*} 1 / * 1$. INR denotes international normalized ratio.

${ }^{\dagger}$ Hazard ratios were adjusted for sex, age, race, use of amiodarone, target INR, starting warfarin dose, number of INR tests, and indication for anticoagulation. 


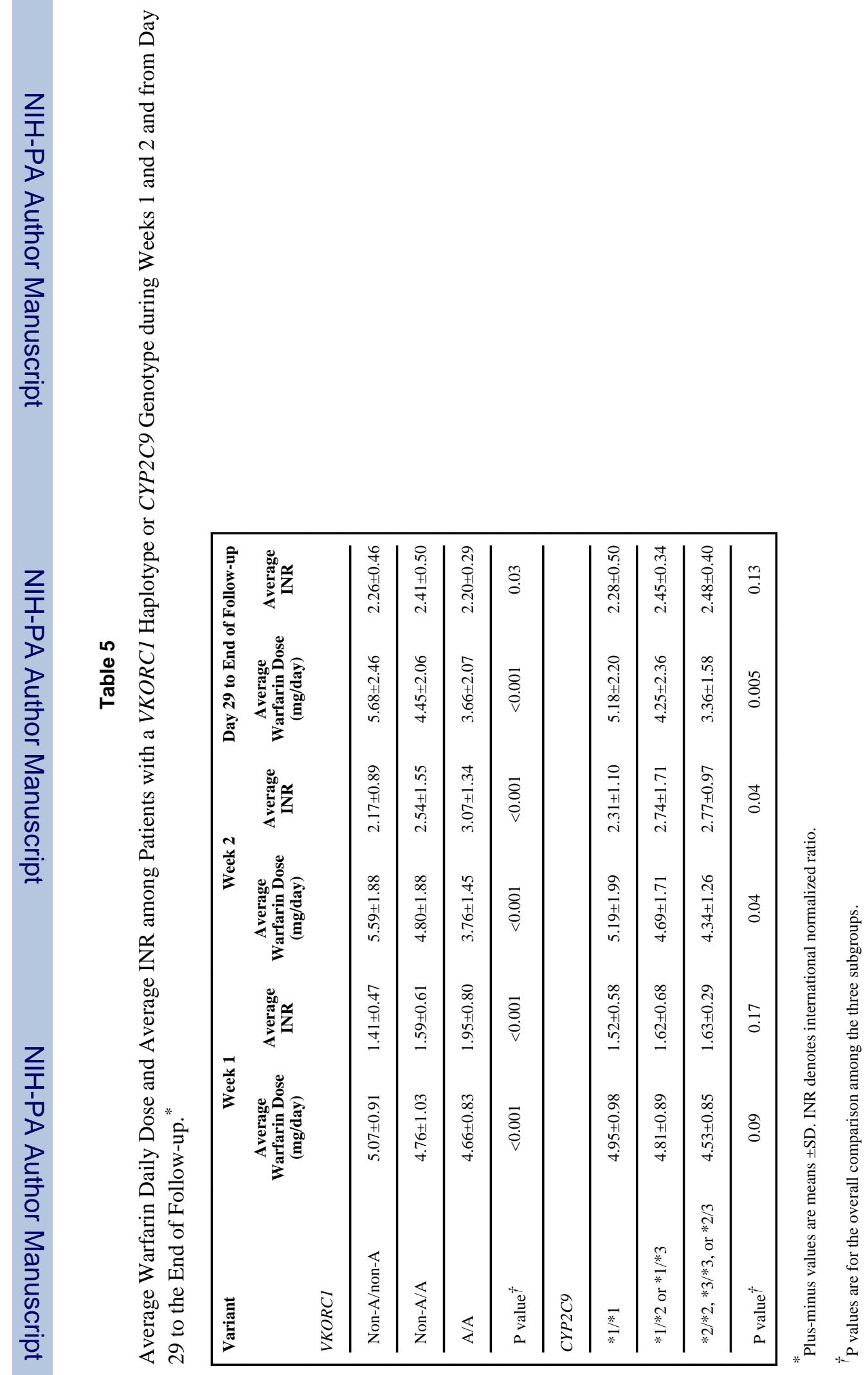

N Engl J Med. Author manuscript; available in PMC 2014 January 17. 